\title{
Analisis Pengaruh Daya Tarik Dan Strategi Pemasaran Terhadap Kepuasan Berbelanja Di Rumah Oxcart
}

\author{
Jaka Atmaja $^{1}$,Teguh Tri Susanto ${ }^{2}$, Khairul Rizal $^{3}$, Chepi Nurdiansyah ${ }^{4}$ \\ ${ }^{1}$ Universitas Bina Sarana Informatika, jaka.jaj@bsi.ac.id \\ ${ }^{2}$ Universitas Bina Sarana Informatika, teguh.tht@bsi.ac.id \\ ${ }^{3}$ Universitas Bina Sarana Informatika, khairul.krl@bsi.ac.id \\ ${ }^{4}$ Universitas Bina Sarana Informatika, chepipunya@gmail.com
}

\begin{abstract}
Abstrak
Berbelanja saat ini telah menjadi suatu yang telah berkembang secara luas baik dengan sistem online maupun secara langsung. Namun sebelum berbelanja biasa orang lebih tertarik dengan berbagai strategi pemasaran yang ditawarkan. Berbagai strategi yang ditawarkan pada dasarnya merupakan daya tarik untuk memancing pelanggan agar berbelanja. Salah satu yang menjadi bahan diskusi penulis adalah "Rumah Oxcart" yang membuka konveksi yang berupa kaos, jaket dan kemeja. Untuk mengetahui daya tarik dan strategi pemasaran Rumah Oxcart terhadap kepuasan berbelanja maka peneliti melakukan penelitian dengan menggunakan metode penelitian kuantitatif, dengan pengumpulan data berupa penyebaran kuesioner kepada para pelanggan yang berbelanja di Rumah Oxcart. Hasil penelitian didapatkan bahwa terdapat pengaruh yang signifikan antara Daya Tarik dan Strategi Pemesaran terhadap Kepuasan Berbelanja di Rumah Oxcart.
\end{abstract}

Kata Kunci: daya Tarik ; Strategi Pemasaran

\begin{abstract}
But before buying ordinary people are more interested in various marketing strategies offered. The various strategies offered for sale are attractive for sale. One of the discussions was "Oxcart House" which opened a convection consisting of t-shirts, jackets and shirts. To find out the attractiveness and marketing strategy of Oxcart House to purchase satisfaction, the study conducted research using quantitative research methods, by collecting data in the form of questionnaires to customers who bought at Oxcart House. Research results obtained from the significant facts between Attractiveness and Recovery Strategy on Shopping Satisfaction at Oxcart Homes.
\end{abstract}

Keywords: Attraction ; Marketing Strategy

SSN: 2355-0287, E-ISSN: 2549-3299

http://ejournal.bsi.ac.id/ejurnal/index.php/jika 


\section{PENDAHULUAN}

Aktifitas belanja yang selama ini dilakukan oleh kebanyakan orang selalu dilakukan baik secara online maupun langsung. Meskipun tidak kalah dengan belanja online belanja yang dilakukan secara langsung selalu dilakukan oleh kebanyakan orang baik muda, tua, maupun remaja. Banyak berbagai faktor yang mendukung orang untuk berbelanja, aik karena faktor kebutuhan atau keinginan. Daya tarik barang tampilkan terkadang membuat orang tertarik terhadap hal tersebut. Banyak barang yang ditampilan dipajang untuk menarik minat pelanggan. Sebelum melakukan pembelian biasa pelanggan tertarik terhadap barang yang dibeli karena barang tersebut menarik minat pelanggan. Pada dasarnya daya tarik orang terhadap suatu barang berbedabeda. Ada yang tertarik lalu langsung membeli, ada yang hanya melihat lihat terlebih dahulu, ada yang memang ragu atau bingung.

Namun daya tarik sutu iklan akan lebih lengkap lagi jika dibantu melalui strategi periklanan. Dalam stategi beriklan yang bagus maka akan menarik minat pelanggan. Strategi periklanan termasuk didalamnya adalah mempromosikan suatu barang baik melalui media cetak maupaun dari mulut kemulut. Promosi yang baik akan membantu proses pemasaran dapat berjalan dengan baik. Suatu proses pemasaran dapat berjalan dengan baik juga harus didukung oleh sarana dan prasana yang dapat mendukung hal tersebut. Banyak orang yang memanfaatkan stategi pemasaran sebagai awal pengenalan barang yang akan dijual atau ditawarkan kepada pelanggan. Pelanggan yang awalnya tidak mengetahui produk illan yang ditawarkan akan berubah menjadi mngerti karena strategi pemasran tersebut.

\section{KAJIAN LITERATUR}

\section{A. Daya Tarik}

Tjiptono

(2012:78)

mendefinisikan iklan sebagai suatu proses persuasi yang tidak langsung, yang didasari pada informasi tentang kelebihan suatu produk yang disusun sedemikian rupa sehingga menimbulkan rasa menyenangkan yang akan merubah pikiran orang untuk melakukan tindakan atau pembelian.

Karena daya tarik sebuah iklan atau power of impression dari suatu iklan adalah seberapa besar iklan mampu memukau atau menarik perhatian pemirsanya (Indiarto, 2006).

Dalam menampilkan pesan iklan yang mampu membujuk, mampu membangkitkan dan mempertahankan ingatan konsumen akan produk yang ditawarkan, memerlukan daya tarik bagi pemirsa sasaran. Daya tarik iklan sangat penting karena akan meningkatkan keberhasilan komunikasi dengan pemirsa (Sutisna, 2003).

Morrisan (2007) mengemukakan bahwa suatu daya tarik iklan adalah "something that moves people, speaks to their wants or needs, and excites their interest". (sesuatu yang menggerakan orang, berbicara mengenai keinginan atau kebutuhan mereka dan membangkitkan ketertarikan mereka).

\section{B. Kepuasan}

Westbrook \& Reilly (dalam Tjiptono 2014:353) berpendapat bahwa: "Kepuasan pengunjung adalahrespon emosional terhadap pengalamanpengalaman berkaitan 
dengan produk atau jasa tertentu yang dibeli, gerai retail, atau bahkan pola perilaku (seperti perilaku berbelanja atau perilaku pembeli), serta pasar secara keseluruhan. Respon emosional dipicu oleh proses evaluasi kognitif yang membandingkan persepsi (atau keyakinan) terhadap obyek, tindakan atau kondisi tertentu dengan nilai-nilai (atau kebutuhan, keinginan dan hasrat) individual."

$\begin{array}{lr}\text { Kepuasan adalah tingkat } \\ \text { perasaan seseorang } & \text { setelah } \\ \text { membandingkan kinerja/hasil } & \text { yang } \\ \text { dirasakannya dengan harapannya, Oliver } \\ \text { (dalam Supranto 2011:233). }\end{array}$

Kepuasan konsumen menurut Kotler (2006:26) merupakan fungsi dari pandangan terhadap kinerja produk atau jasa dan harapan konsumen. Kepuasan merupakan fungsi dari persepsi kesan atas kinerja dan harapan. Jika kinerja berada di bawah harapan maka konsumen tidak puas, jika kinerja memenuhi harapan maka konsumen puas, jika kinerja melebihi harapan maka konsumen sangat puas atau senang.

Tjiptono (2008:87) ada enam konsep inti yang memiliki kesamaan diantara beragamnya cara mengukur kepuasan konsumen, yaitu:

1) Kepuasan Konsumen keseluruhan (Overal Customer Satisfaction)

Cara yang paling sederhana untuk mengukur kepuasan konsumen adalah langsung menanyakan kepada konsumen seberapa puas mereka dengan produk atau jasa spesifik tertentu.

2) Dimensi Kepuasan konsumen

Berbagai penelitian memilah kedalam komponen-komponennya. Umumnya proses semacam itu terdiri atas empat langkah: a. mengidentifikasi dimensidimensi kunci konsumen atau Konsumen.

b. Meminta Konsumen menilai produk atau jasa perusahaan berdasarkan

item-item spesifik seperti kecepatan layanan atau keramahan staf

konsumen.

c. Meminta konsumen menilai produk atau jasa pesaing berdasarkan itemitem spesifikyang sama.

d. Meminta konsumen untuk menentuukan dimensi-dimensi yang menurut mereka paling penting dalam menilai kepuasan konsumen keseluruhan.

3) Konfirmasi harapan (confirmation of expectations)

Yaitu kesesuaian atau ketidaksesuaian antara harapan konsumen dengan kinerja aktual produk perusahaan. Dalam hal ini akan lebih ditekankan pada service quality yang memiliki komponen berupa harapan Konsumen akan pelayanan yang diberikan (seperti : kebersihan lokasi, kecepatan pelayanan, keramahan/kesopanan pengelola dan karyawan, dan sifat pertemanan dari karyawan).

4) Minat pembelian Ulang

Kepuasan Konsumen diukur secara behavioral dengan jalan menanyakan apakah konsumen akan berbelanja menggunakan jasa perusahaan lagi. Pelayanan yang berkualitas dapat menciptakan kepuasan konsumen dimana mutu pelayanan tersebut akan masuk 


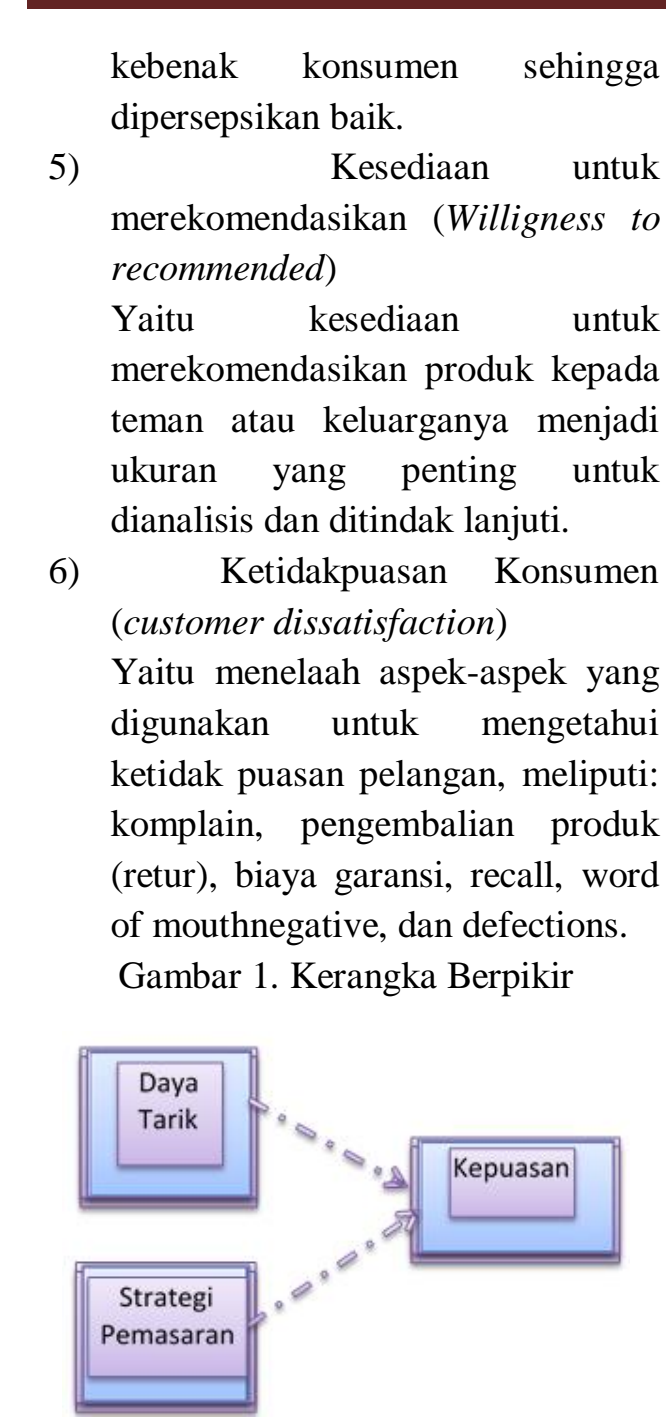

Sumber : Hasil Pemikiran Penulis

\section{Hipotesis}

Dari kajian teori di atas dan penelitian yang relevan, penulis menduga Hipotesis dari gambar di atas adalah sebagai berikut :

H0 : Diduga tidak ada pengaruh antara Daya Tarik dan Strategi Pemasaran terhadap Kepuasan

Ha : Diduga ada pengaruh antara Daya Tarik dan Strategi Pemasaran terhadap Kepuasan

\section{METODE PENELITIAN Tempat dan Waktu Penelitian}

Tempat penelitian berlokasi di Jalan Basuki Rahmat no 116 Duren Sawit Jakarat Timur. Menurut Sugiyono (2011:117) populasi adalah wilayah generalisasi yang terdiri atas objek atau subjek yang mempunyaikualitas dan karakteristik tertentu yang ditetapkan oleh peneliti untuk dipelajari kemudian ditarik kesimpulannya. Populasi untuk penelitian ini adalah 150 orang yang terdiri para pelanggan Rumah Oxcart.

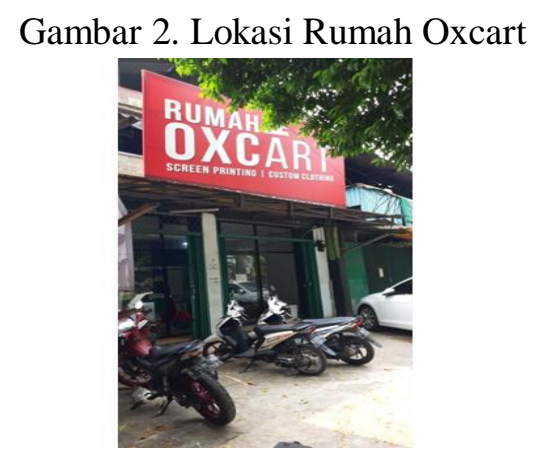

Sumber : Dokumen Pribadi, 2020

Metode pengambilan sampel yang digunakan adalah propability sampling yang artinya setiap unsur populasi mempunyai kemungkinan yang sama untuk dipilih melalui perhitungan sistematis. Menurut Sugiyono (2011:118) "sampel adalah bagian dari jumlah dan karakteristik yang dimiliki oleh populasi tersebut. Dengan teknik pengambilan sampel yaitu Proposional Stratified Sampling karena sample yang diambil berdasarkan tingkat kelas. Responden (sampel) yang dipilih dari populasi, dipilih berdasarkan rumus Slovin yaitu sampel yang akan ditentukan dengan persentase kelonggaran ketidak telitian 10\%, yaitu :

$\mathrm{n}=$ Ukuran sampel

$\mathrm{N}=$ Ukuran populasi $=150$

$\mathrm{e}=$ Tingkat kesalahan $=10 \%$. $=0,1$ Berdasarkan penjelasan di atas maka dengan Metode Slovin / rumus Slovin, didapatkan ukuran sampel berikut: 


$$
n \square \frac{N}{1 \square N \square \rrbracket^{\square}}
$$

$\mathrm{n}=60$ responden

Jadi diketahui dari perhitungan untuk ukuran sampel dengan tingkat kesalahan $10 \%$ adalah 60 responden.

\section{PEMBAHASAN}

Hasil Uji Validitas dan Reliabilitas Instrumen Penelitian Sebelum dilakukan uji analisis terlebih dahulu dilakukan uji validitas dan uji reliabilitas terhadap data yang terkumpul agar memenuhi persyaratan untuk dilakukan analisis selanjutnya.

\section{Uji Validitas}

Uji validitas dilakukan untuk mengetahui apakah instrumen atau item pertanyaan tersebut valid atau tidak. Jika terdapat item pertanyaan yang tidak valid maka harus diganti dengan pertanyaan lain sehingga difahami oleh responden. Untuk memudahkan perhitungan dalam melakukan uji validitas digunakan bantuan program SPSS (Statistical Package for the Social Sciences) for Windows Ver.20,0. Validitas menekankan pada hubungan yang sangat penting antara konsep dan indikator (Puspitawati, 2013).

\section{$\underline{\text { Table 1. Uji Validitas Daya Tarik (X1) }}$}

\begin{tabular}{|c|c|c|}
\hline dik & $\mathrm{x} 1$ total & \\
\hline $\mathrm{x} 1.1$ & Pearson Correlation &, $616 * *$ \\
\hline & Sig. (1-tailed) ,000 & \\
\hline 1.2 & Pearson Correlation &, $752 * *$ \\
\hline & Sig. (1-tailed) ,000 & \\
\hline & Pearson Correlation &, $742 * *$ \\
\hline & Sig. (1-tailed) ,000 & \\
\hline & Pearson Correlation &, $740 * *$ \\
\hline & Sig. (1-tailed) ,000 & \\
\hline & Pearson Correlation &, $640 * *$ \\
\hline & Sig. (1-tailed) ,000 & \\
\hline
\end{tabular}

Table 2. Uji Validitas Strategi Pemasaran (X2)

$\begin{array}{lll}\text { indikator x1total } & \\ \text { x1.1 } & \begin{array}{l}\text { Pearson Correlation } \\ \text { Sig. (1-tailed) ,000 }\end{array} & 529 * * \\ \text { x1.2 } & \begin{array}{l}\text { Pearson Correlation } \\ \text { Sig. (1-tailed) ,000 }\end{array} \\ \text { x1.3 } & \begin{array}{l}\text { Pearson Correlation } \\ \text { Sig. (1-tailed) ,000 }\end{array} \\ \text { x1.4 } & \begin{array}{l}\text { Pearson Correlation } \\ \text { Pear } \\ \text { Sig. (1-tailed) ,000 }\end{array} \\ \text { x1.5 } & \begin{array}{l}\text { Pearson Correlation } \\ \text { Sig. (1-tailed) ,000 }\end{array} \\ & \end{array}$

$\underline{\text { Table 3. Uji Validitas Kepuasan (Y) }}$

\begin{tabular}{|c|c|c|}
\hline \multicolumn{3}{|c|}{ indikator } \\
\hline $\mathrm{x} 1.1$ & Pearson Correlation &, $568 * *$ \\
\hline & Sig. (1-tailed) ,000 & \\
\hline & Pearson Correlation &, $736 * *$ \\
\hline & Sig. (1-tailed) ,000 & \\
\hline & Pearson Correlation &, $706^{* *}$ \\
\hline & Sig. (1-tailed) ,000 & \\
\hline & Pearson Correlation &, $695^{* *}$ \\
\hline & Sig. (1-tailed) ,000 & \\
\hline & Pearson Correlation &, $660 * *$ \\
\hline & Sig. (1-tailed) ,000 & \\
\hline
\end{tabular}

\section{(Sumber : Hasil Olah Data SPSS 2019)}

Berdasarkan hasil perhitungan program SPSS atas responden yang berjumlah 150 orang, untuk mengetahui suatu instrumen dikatakan valid, yaitu dengan membandingkan koefisien korelasi product moment dengan taraf signifikansi sebesar $\alpha=0,05$ (5\%). Jika signifikansi (1-tailed) kurang dari 0,05, maka butir pernyataan tersebut dinyatakan valid dan begitu pula sebaliknya.

\section{Uji Reliabilitas}

Menurut H. Djaali Dan Muljono (2007) Realibilitas yang berasal dari kata realibility berarti sejauhmana hasil suatu pengukuran dapat dipercaya. Suatu

SSN: 2355-0287, E-ISSN: 2549-3299

http://ejournal.bsi.ac.id/ejurnal/index.php/jika 
hasil pengukuran hanya dapat dipercaya apabila dalam beberapa kali pelakasanaan pengukuran terhadap kelompok subyek yang sama, diperoleh hasil pengukuran yang relatif sama, sealma aspek yang diukur dalam diri subyek memang belum berubah.

Table 4. Uji Realibilitas Daya Tarik (X1)

Reliability Statistics

\begin{tabular}{|c|c|}
\hline $\begin{array}{c}\text { Cronbach's } \\
\text { Alpha }\end{array}$ & N of Items \\
\hline .725 & 5 \\
\hline
\end{tabular}

Sumber : Hasil Olah Data SPSS 2019

Table 5. Uji Realibilitas Strategi Pemasaran (X2)

Reliability Statistics

\begin{tabular}{|r|r|}
\hline $\begin{array}{c}\text { Cronbach's } \\
\text { Alpha }\end{array}$ & N of Items \\
\hline 689 & 5 \\
\hline
\end{tabular}

Table 6. Uji Kepuasan (Y)

Reliability Statistics

\begin{tabular}{|r|r|}
\hline $\begin{array}{l}\text { Cronbach's } \\
\text { Alpha }\end{array}$ & N of Items \\
\hline .714 & 5 \\
\hline
\end{tabular}

Sumber : Hasil Olah Data SPSS 2019

diperoleh nilai Cronbach's Alpha sebesar lebih besar dari 0,60. Dengan demikian item pernyataan untuk seluruh variabel Kepuasan pembeli (Y) dinyatakan reliabel

Table 7. Analisa Regresi Berganda

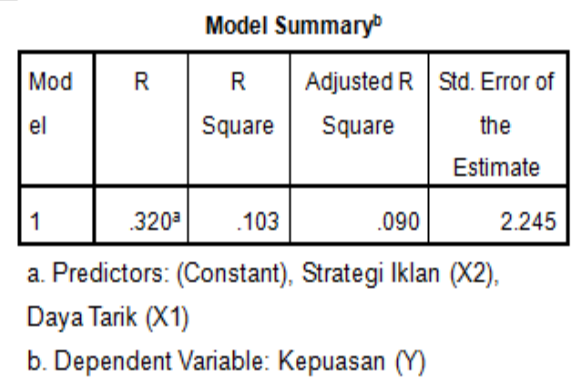

Sumber : Hasil Olah Data SPSS 2019

\section{KESIMPULAN}

Berdasarkan hasil penelitian yang didapatkan dari tabel diatas diperoleh angka $\mathrm{R}$ sebesar 0,320. Hal ini menujukkan bahwa terjadi pengaruh yang antara Daya Tarik dan Strategi Pemasaran terhadap Kepuasan berbelanja.

\section{DAFTAR PUSTAKA}

Fandy Tjiptono. 2008. Prinsip Total Quality Service. Yogyakrta: Andi Offset.

H. Djaali Dan Muljono. 2007.

Pengukuran Dalam Bidang Pendidikan.

Jakarta: PT. GRASINDO.

Indiarto, F. (2006).Studi Mengenai Kekhawatiran dalam Proses Penyampaian Pesan Iklan. Jurnal Sains Pemasaran Indonesia, 3, 243-262.

Kotler, Phillip. 2006. Manajemen Pemasaran. Jakarta: PT Indeks.

Morisan. 2007. Perikalanan (Komunikasi Pemasaran Terpadu). Jakarta: Ramadina Prakasa.

Puspitawati, H., Herawati, T., Hastuti, D., Sunarti, T., \& Sarma, M. (2015). Pengembangan model operasional pendataan ketahanan keluarga untuk kegiatan pembangunan di tingkat kabupaten. Laporan penelitian, Kementerian Pemberdayaan Perempuan dan Perlindungan Anak-RI dengan Pusat Kajian Gender dan Anak-IPB. 
Supranto. 2011. Pengukuran Tingkat Kepuasan Pelanggan. Jakarta: Rineka Cipta.

Sugiyono. 2011. Metode Penelitian Kuantitatif, Kualitatif, dan R\&D. Bandung: AFABETA, cv.

Sutisna, (2001). Perilaku Konsumen dan Komunikasi Pemasaran. Bandung: Remaja Rosdakarya.

Tjiptono, Fandi. 2012. Strategi

Pemasaran. Edisi Kedua. Penerbit Andy,

Yogyakarta

Tjiptono, Fandy. 2008. Service Management. Yogyakarta: CV. Andi Offse.

\section{BIODATA PENULIS}

1. Jaka Atmaja, S.Ikom, MM. lahir di Jakarta, 26 Februari 1984 aktif sebagai Dosen di Fakultas Ilmu Komunikasi \& Bahasa Universitas Bina Sarana
Informatika Jakarta dari tahun 2015 sampai dengan sekarang.

2. Teguh Tri Susanto, S.Sn., M.M. Lahir di Bandung, 18 Januari 1980. Aktif sebagai dosen di Program Studi Periklanan, Fakultas Komunikasi \& Bahasa, Universitas Bina Sarana Informatika.

3. Khairul Rizal, M.Kom, Lahir di Jakarta, 6 Agustus 1983. Aktif sebagai dosen di Program Studi Sistem Informasi, Fakultas Teknik \& Informatika, Universitas Bina Sarana Informatika.

4. Chepi Nurdiansyah, S.Ikom, M.M Lahir di Jakarta 28 Juni 1986, aktif sebagai Dosen di Fakultas Ilmu Komunikasi \& Bahasa Universitas Bina Sarana Informatika Jakarta dari tahun 2015 